\title{
Auge y ocaso del shule icufista en Argentina (1941-1968)
}

\author{
Nerina Visacousky \\ UNSAM-Conicet \\ nerivisa@hotmail.com
}

\section{Origenes de una educación judia para argentinos}

Este trabajo analiza el proceso de auge y ocaso de las escuelas idiomáticas y complementarias en ídish adheridas al Idisher Cultur Farband (ICUF) entre 1941 y 1968. El ICUF fue (y es aún) una Federación de entidades judias laicas y progresistas, surgida como Yiddisher Kultur Farband (YKUF) en el marco de un congreso de intelectuales judíos antifascistas ligados al comunismo y al socialismo, realizado en París entre el 17 y el 22 de septiembre de $1937 .{ }^{1}$ En aquel congreso, los delegados de 23 países manifestaron su preocupación por el avance del fascismo en Europa y la situación de los republicanos en la Guerra Civil Española y se comprometieron a difundir, a través de publicaciones, escuelas y actividades culturales, el "judeo-progresismo" (icufismo) en sus países de residencia. ${ }^{2}$ En representación de Argentina y Uruguay, había viajado el reconocido intelectual idishista y simpatizante comunista Pinie Katz (Odesa, 1881 - Buenos Aires, 1959), quien se convirtió luego en el principal organizador del Congreso Judío Latinoamericano realizado en Buenos Aires en 1941, donde las máximas de París, "luchar contra el fascismo, el antisemitismo, la discriminación y defender la cultura laica idishista", dieron nacimiento al ICUF en América Latina, con la participación de 57 instituciones del país, Brasil, Uruguay y Chile, en nombre de 8.900 asociados (Visacovsky, 2015: 97). Desde entonces, la federación ICUF brindó marco político-ideológico a instituciones ya existentes y promovió la creación de otras nuevas. Bajo el clima alian-

1. En 1938, el Congreso del YKUF se replicó en Nueva York y participaron 1.204 delegados americanos y canadienses (Kinoshita, 2000).

2. Isaac Gliksberg, "Um aporte valioso", Revista ASA, Río de Janeiro, no 114, septiembre-octubre de 2008, p. 7.

(Archivos, año VI, $\mathrm{n}^{\circ} 11$, septiembre de 2017, pp. 121-141) 
cista del frentepopulismo que la Internacional Comunista inauguró en 1935 y el rol de la URSS y el Ejército Rojo durante la Segunda Guerra Mundial, nació una gran responsabilidad local por homenajear y preservar la memoria y el legado del Idishkait ${ }^{3}$ y así los shules icufistas se multiplicaron. En el año 1958 el ICUF afirmaba nuclear 15 escuelas idiomáticas en todo el país con 2.500 chicos, varios cuadros filodramáticos, cerca de 50 instituciones culturales, tres publicaciones, una editorial propia y organizaciones femeninas y juveniles, al tiempo que enfatizaba su condición de movimiento comprometido con la defensa de la enseñanza laica y estatal. ${ }^{4}$ Sin embargo, cuando en la década del 60 la generación nativa apareció en escena, la continuidad del shule y la enseñanza del ídish comenzaron a perder sentido para sus protagonistas. A lo largo de su historia, en los cargos dirigentes del ICUF y en las comisiones directivas de las entidades adheridas participaron algunos militantes, y la simpatía hacia el Partido Comunista (PC) fue generalizada. Sin embargo, a pesar de su centralidad en la vida institucional, se verá cómo la adopción de "línea para la colectividad judia" del PC, a veces fue acompañada y otras veces resistida por activistas y público de esta red. Interesa en este trabajo poner el foco en aquellas iniciativas vinculadas a la cuestión idiomática y educativa.

Las primeras experiencias formales de educación judía en Argentina datan de fines de siglo XIX, cuando llegaron numerosas familias provenientes del Imperio Ruso y, en su mayoría, bajo acuerdos entre la empresa colonizadora agraria Jewish Colonization Association (JCA) y gobiernos provinciales. ${ }^{5}$ Hacia 1914, el tercer censo nacional argentino estimaba un total de 81.915 inmigrantes judíos viviendo en el país. Con sus dichas y sus desgracias, las vivencias vinculadas a la colonización son, a menudo, referidas como el símbolo más pleno de la integración del colectivo israelita a la "argentinidad". Así lo expresan diversos relatos, como el mítico Los gauchos judios de Alberto Gerchunoff (1910). Ciertamente, el país de principios de siglo XX no era la soñada tierra de promisión que esperaban, pero tampoco se equiparaba con sus contextos de proveniencia, en sus niveles de discriminación, racismo

3. Concepto similar a idishismo, que refiere no sólo a la lengua ídish, sino a todo el universo cultural, político e ideológico constituido en su tierra de origen.

4. "Gran acto del ICUF en defensa de la enseñanza laica", Tribuna, año VI, n 310 , 19 de septiembre de 1958, p. 2.

5. La "Jewish", fundada en Londres por el barón Maurice de Hirsch en 1891, patrocinó vastos asentamientos en las provincias de Santa Fe, La Pampa, Santiago del Estero, Buenos Aires y principalmente Entre Ríos, en un total de 617.658 hectáreas (Feierstein, 2007: 66). Otras experiencias fuera de la Jewish tuvieron lugar en Chaco y Río Negro. Sobre las acciones de la JCA, ver Jewish Colonization Association. Su obra en Argentina, 1891-1941, Buenos Aires, 1942. 
y violencia (Devoto, 2015: 18). Las dificultades de la vida agraria, las posibilidades de progreso en las ciudades y las políticas nacionales volcadas a fomentar el desarrollo industrial (sobre todo a partir de la crisis de Wall Street en 1929 y el cierre de los mercados) constituyeron los principales factores por los cuales, masivamente, la población del campo comenzó a trasladarse, especialmente, a Córdoba, Rosario y Buenos Aires. Por eso, en 1935 sólo un $11 \%$ de los 191.000 judíos que habitaban la Argentina residian en las colonias agrícolas (Avni, 1983). Interesa mencionar la vida socioeducativa de las colonias, porque allí las bibliotecas, teatros y escuelas de primeras letras cumplieron un rol fundamental, en tanto constituyeron la única alternativa pedagógica en poblados provinciales alejados de las ciudades. Así, la educación en las colonias judias fue pionera experiencia de integración que, no exenta de conflictos, se fue amoldando a los principios de la Ley 1.420 (1884), los objetivos de alfabetización masiva y la normativa patriótica establecida por el Consejo Nacional de Educación. ${ }^{6}$ Esas escuelitas de campo constituyeron un ámbito dónde niños judíos y criollos aprendieron juntos a leer y escribir en castellano y también, casi naturalmente, unos y otros se mezclaron entre costumbres locales y tradiciones del pueblo hebreo. La impronta de aquella experiencia emergida de una colectividad particular pero abierta a la comuna, y la búsqueda permanente de un equilibrio entre el propio credo y los contenidos de esa nueva identidad argentina, mucho se vincula con los presupuestos de educación judeoprogresista que años después desarrollarian las instituciones adheridas al ICUF en Argentina.

\section{La izquierda judia de Buenos Aires}

Las familias judias radicadas en Buenos Aires fueron aumentando a medida que crecía la migración interna antes referida, y llegaban nuevos contingentes en los años de entreguerras. A pesar de una común iden-

6. El Consejo Nacional de Educación (CNE) se creó en enero de 1881 con el fin de gobernar las escuelas primarias de la Capital Federal (establecida en la provincia de Buenos Aires en 1880) y los extensos territorios nacionales. Sin embargo, el lento desarrollo del programa político y educativo establecido en la Ley 1.420 -siendo concebida como herramienta principal para la formación ciudadana y argentinización de los inmigrantes- llevó a las elites dirigentes a tomar nuevas medidas y en octubre de 1905 se sancionó la ley 4.874, presentada por el diputado Manuel Láinez, por la cual se autorizaba al CNE a establecer y supervisar escuelas elementales en las provincias que así lo solicitaran. Prácticamente todas suscribieron a la ayuda ofrecida por la Nación y en los años 30 la mayoría de las jurisdicciones contaba con mayor cantidad de escuelas Láinez creadas por esa ley y administradas por el CNE, que provinciales creadas por la Constitución Nacional y administradas por la gobernación. 
tificación vinculada a los aspectos religiosos, al provenir de diferentes países y culturas eran muy disimiles sus lenguas, instituciones y costumbres. Una postal de los años 20 y 30 en los barrios porteños mostraba la convivencia de ortodoxos con sus típicas vestimentas, obreros anarquistas o socialistas participando en manifestaciones, comerciantes "rusos" y "turcos" montando sus negocios, sastres, carpinteros, rufianes, actrices, músicos, ricos y pobres. En definitiva, los cementerios, las sinagogas, las bibliotecas, las publicaciones y también las primeras escuelas eran la expresión misma de aquella pluralidad. Sin embargo, a grandes rasgos, los de origen ashkenazi, que hablaban idish, tenian un perfil secular y provenían de Europa Central y del Este, se destacaban frente a otros grupos, como los de origen sefaradi, vinculados a un pasado en la Península Ibérica y el Imperio Otomano. ${ }^{7}$

Desde principio de siglo XX, gran parte de los ashkenazies de origen obrero simpatizaron o se integraron a partidos políticos y agrupaciones de izquierda existentes en Argentina, pero que también conocían en Europa; las causas marxistas los habian convocado a luchar por los derechos universales de los trabajadores, aunque, al mismo tiempo, generaban espacios de socialización y politización al interior de su grupo de pertenencia étnica (Bilsky, 1989; Díaz, 2016). Así, a menudo, en una casa de familia, o alquilando un pequeño local, editaban revistas y abrian bibliotecas en ídish. Unos años más tarde llegarian las escuelas complementarias para niños y adolescentes en ese idioma. Funcionaban a contraturno de la escuela pública estatal obligatoria, y sus objetivos y contenidos reflejaban la cultura e ideología de sus dirigentes. ${ }^{8}$ En el mundo idishista de los años 30, socialistas-bundistas, anarquistas, comunistas y sionistas manifestaban una cultura común pero identificada con diferentes propuestas partidarias. Ese enfrentamiento, obviamente, era menor en los pueblos o ciudades con poca población judia, donde carecía de sentido diversificar esfuerzos y más aún frente a una generalizada movilización antifascista y el devenir de la Segunda Guerra Mundial. En cambio, en Buenos Aires y su periferia, tomaron forma tres redes escolares idishistas de izquierda, que crecieron notablemente en la segunda mitad de la década y con énfasis en los 40. En primer lugar, existían escuelas orientadas por el Partido Obrero Judío

\section{Ashkenaz significa en hebreo Alemania y Sefarad, España.}

8. Por ejemplo, el Centro Literario y Biblioteca Israelita Max Nordau de la ciudad de La Plata se inauguró en 1912 y su escuela comenzó a funcionar en 1932; la Asociación Cultural Israelita de Córdoba había iniciado como biblioteca en 1913 y fue en el año 1931 que abrió su escuela; la Sociedad Cultural Israelita Isaac León Peretz de Santa $\mathrm{Fe}$, asimismo, se inauguró en 1912, y su escuela comenzó en la década del 30. Se trataba de experiencias informales para grupos reducidos de niños. 
Bund, ${ }^{9}$ cuyos dirigentes se autodefinian autonomistas, socialistas y marxistas de la Segunda Internacional, no acordaban con el sionismo ni con el comunismo y coincidian con el programa del Partido Socialista Argentino, aunque no se subsumían en él. En segundo lugar, estaban las escuelas del partido Linke Poale Sion (Trabajadores de Sion de Izquierda), quienes se autodefinían sionistas-marxistas y perseguían ideales emancipatorios inspirados en el ucraniano Dov Ber Bórojov (1881-1917) acerca de la necesidad de reunir al pueblo judío en un mismo territorio, como paso previo a la revolución socialista. En 1921 se habian escindido de la sección que formó "la derecha" de Poale Sion para adscribir a la Komintern, pero hacia fines de los años 30 la abandonaron y trabajaron en pos de la creación de un Estado judío socialista con modelos cooperativos de trabajo (lo que años más tarde resultaría plasmado en las experiencias de los kibutz israelíes). Finalmente, la tercera red fue la que quedó definitivamente vinculada a la Komintern y luego al Partido Comunista Argentino, a través de la Sección Idiomática Judía (Idsektzie o Idische Sektzie des Komunistishes Partei) y cuyas escuelas autodenominadas "obreras, marxistas y leninistas" en los años 20 (primera fase) y "populares" en los años 30 (segunda fase), conformarian el antecedente inmediato de las escuelas "laicas" (tercera fase) que adhirieron al ICUF en 1941. Este trabajo se ocupa únicamente de esta última red, la icufista, y en su tercera fase.

Desde 1935, a partir del VII Congreso de la Internacional Comunista, los militantes argentinos habian tendido puentes para formar coaliciones con los sectores democráticos, y así también los icufistas. En esa coyuntura donde, por un lado, el "fascismo criollo" venía acompañado de elementos antisemitas ${ }^{10} \mathrm{y}$, por otro, los judíos comunistas dejaban de ser obreros para ir transformándose en clases medias, la primacía de la consigna "frentepopulista y antifascista" en desmedro de aquella de "clase contra clase" (1928-1935), cuadró muy bien para fortalecer su red institucional. El "permiso" partidario otorgado a la militancia judía para forjar alianzas con la "burguesía progresista" habilitó a los

9. "Bund", en ídish, significa Unión y refiere al Partido Obrero Judío creado en Vilna, Lituania, en 1897. El nombre completo era Algemeyner Yiddisher Árbeter Bund fun Rusland, Poyln un Lite: Unión General de los Trabajadores Judios de Rusia, Polonia y Lituania. El uso del concepto "bundismo" ha referido a este movimiento político que tuvo gran protagonismo en la conformación del Partido Obrero Social Demócrata Ruso en 1898 y, hasta su aniquilación durante la Shoá, habia sido liderado internacionalmente por la dirigencia polaca idishista. Ver más en Laubstein (1997).

10. Debe tenerse en cuenta aquí, que el "antisemitismo criollo" no sólo refería a la derecha nacionalista, sino también a la izquierda nacionalista que culpaba a los "judíos capitalistas, dueños de los frigoríficos ingleses" de la dependencia económica de la Argentina (Halperin Donghi, 2003: 115). 
dirigentes de la Idsektzie a propiciar un acercamiento a sus coterráneos idishistas de mejor posición económica, sin afectar su lealtad al partido. Es decir, la etapa frentepopulista les permitió conciliar sus intereses étnicos y culturales con aquellos político-partidarios. Varios judíos que militaban en sindicatos se involucraron con el icufismo a partir de los años 40. En ciertos casos se transformaron en activistas de escuelas y en otros, se ubicaron en la periferia de las entidades, desarrollando sobre todo labor periodística. En el nuevo contexto, la dirigencia icufista buscó otorgarle a la red escolar un marco de legalidad cumpliendo los requisitos y la normativa estatal. A diferencia del tiempo de las escuelas obreras, los shules icufistas evitaron hacer explícitos contenidos a favor del comunismo, como mecanismo de protección frente a las autoridades nacionales, pero también porque la nueva sensibilidad antifascista (Pasolini, 2013: 21) y el llamado a la unidad de los frentes populares habian morigerado el discurso radicalizado contra el "enemigo burgués" y el "enemigo social-fascista". Sin embargo, en la escena política argentina, los sectores nacionalistas conservadores y católico-integristas adquirían un protagonismo cada vez mayor, revivieron el mito del "judíobolchevique". A pesar de su presencia desde los tiempos del Centenario y la Semana Trágica, el mito resurgió a partir de la amenaza comunista que en 1936 supuso la ayuda de Moscú a los republicanos, durante la Guerra Civil Española. Tal como había ocurrido con las escuelas obreras marxistas-leninistas en 1932 (y otras de izquierda idishista), las escuelas "populares" fueron clausuradas en 1937 y el ídish observado y condicionado su uso en actividades de enseñanza y actos públicos. Personajes del conservadurismo argentino como el senador Matías Sánchez Sorondo afirmaban con absoluta convicción que ese idioma constituía el "código de los soviets" para operar en Argentina (Visacovsky, 2012). Paralelamente a esa disposición surgía el Yiddisher Kultur Farband en Francia, como antes se mencionó, y al iniciar la Segunda Guerra Mundial las escuelas en ídish comenzaron a resurgir una vez más. En 1941 se sumaron entidades ya existentes en Mendoza, Tucumán, Córdoba, Santa Fe y también las de Uruguay y Brasil. Al finalizar la guerra, en 1945, la Unión Soviética y su Ejército Rojo, que habian enfrentado al nazismo, despertaron numerosas simpatías y las escuelas del ICUF ganaron una notable adhesión en la "calle judía". A sus filas se integraron grupos que habian colaborado con los republicanos y más tarde con los aliados. Gracias al progreso económico de los años 40 se compraron edificios propios y con el nombre de Veltleje Shuln (escuelas laicas), se consolidaron y fueron reconocidas como escuelas idiomáticas complementarias por el Consejo Nacional de Educación y los Consejos Provinciales. Asimismo, contaron con el apoyo económico y reconocimiento del Comité Educativo de la Asociación Mutual Israelita 
Argentina (AMIA) (Vaad Hajinuj); entre 1943 y 1944, los shules icufistas Jaim Zhitlovsky de Villa del Parque e I.L.Peretz de Villa Lynch, que eran los más concurridos, fueron incorporadas a su politica de subsidios, mientras que otros cinco shules icufistas se sumaron hacia el final de esa década. Cabe destacar que, en el marco de la educación judía, las tres tendencias izquierdistas (bundistas, linkepoalesionistas e icufistas), eran las más populares para entonces y superaban en cantidad de alumnos a las de sectores sionistas conservadores, y otras minoritarias de grupos religiosos (Zadoff, 1994). Sin embargo, la creación del Estado de Israel en 1948 y el inicio de la Guerra Fría posteriormente fueron determinando nuevas polarizaciones en el campo comunitario. En diciembre de 1952, la dirigencia icufista se negó a firmar una condena que impulsaba la DAIA ${ }^{11}$ condenando a la URSS por los juicios de Praga y los (hasta entonces, "supuestos") crimenes a escritores judíos antifascistas. Aquello culminó con la expulsión de los shules del ICUF y la quita del subsidio que recibían. Sin embargo, el firme idealismo de ese colectivo generó decenas de cooperativas de crédito y campañas solidarias que financiaron la continuidad de la red escolar. Así, al iniciar la década del 60 una nueva generación nacida en Argentina y formada en el entorno icufista se incorporaba a la vida institucional. Empero, la defensa de la educación laica estatal, la militancia latinoamericana inspirada en el caso cubano, el nuevo rol de la mujer, la revolución sexual, y otros factores que movilizaban a la juventud, inclinaban a los hijos de los inmigrantes a involucrarse en otros espacios políticos y sociales, entre los cuales se destacaba el ámbito universitario. Esa participación en contextos más amplios, fuera del grupo judío, era el fruto de una integración social exitosa, pero a su vez, gestaba otro proceso en su interior: inauguraba el principio del final de la red de shules icufistas. Fue entonces cuando los activistas propusieron apostar a la expansión de actividades recreativo-formativas durante el tiempo libre: los kinder clubes $^{12}$ de los sábados, los jardines de infantes alternativos, un amplio despliegue deportivo y las colonias vacacionales Zumerland (Diamant y Feld, 2000). Con esas actividades, vanguardistas en su modalidad, iniciaba una suerte de "cuarta fase" de la educación judeo-progresista (Visacovsky, 2015). Una de las principales voces a favor de apoyar esa transformación y diagnosticar la "transitoriedad" de las escuelas en ídish era la de Rubén Sinay, dirigente, periodista militante y miembro de la

11. Delegación de Asociaciones Israelitas Argentinas. Creada en Buenos Aires en 1935 con el propósito de representar politicamente a la colectividad judía en Argentina.

12.El kinder club o club infantil surgió como un espacio extraescolar para niños de 6 a 12 años, una propuesta centrada en el juego creativo, el deporte y el trabajo grupal con contenido ideológico. Para los adolescentes de 13 a 17 años funcionaba el joven club. 
Comisión Israelita del Partido Comunista. Durante los años de Guerra Fría, Sinay expresó las ideas del partido para la colectividad en temas de política nacional e internacional, pero también argumentó acerca de los objetivos de los shules, la enseñanza del ídish y la formación de los niños. Interesa aquí, a través de su discurso, analizar la posición del partido, sus efectos en la red y la perspectiva de otros actores centrales como las maestras (en ídish, lererkes) y activistas. Finalmente se dejarán planteados una serie de factores sociales y políticos que contribuyen a explicar el ocaso de los shules icufistas.

\section{Semblanzas de Rubén Sinay}

Con el triunfo de Juan Domingo Perón en febrero de 1946, el Partido Comunista Argentino, a partir de su XI Congreso realizado en agosto, se replanteaba las estrategias a seguir para captar a las masas "desviadas" hacia el nuevo fenómeno peronista (Altamirano, 2001). En ese sentido, la cúpula del PCA entendió que uno de sus principales problemas para esclarecer a la clase trabajadora era la gran cantidad de inmigrantes dirigiendo en los sindicatos. En consecuencia, resolvió "acriollar" al partido y eso implicó desplazar a los extranjeros de ciertos cargos. Varios de los judíos fueron inducidos por el PC a militar en ámbitos de la colectividad israelita y, por eso, fue entre fines de los años 40 y principios de los 50 cuando aparecieron nuevas figuras en el entorno ideológico del ICUF, que a su vez conformaron y dieron nuevo impulso a la Comisión Israelita del PC (antes, Idsektzie). ${ }^{13}$ Los miembros y allegados a esa comisión participaban en la prensa idishista,${ }^{14}$ en cargos directivos del ICUF, y varios se destacaron como militantes y activistas paralelamente. Ese fue el caso de Gregorio Lerner, Iankl Guilemberg, José Freidkes, Ioel Linkovsky, Benito Sak, Sansón Drucaroff, Tzalel Blitz, Ángel Grushka, Mauricio Rascovan, León Kolbovsky, Julio Schverdfinger, Luis Goldman y Meyer Kot, entre otros. Sin embargo, la figura del PC más prominente del período fue Rubén Sinay (1918-1990). Destacado cuadro dirigente, publicó decenas de $\operatorname{libros}^{15} \mathrm{y}$ fue redactor principal en dos publicaciones periódicas leídas asiduamente por el público icufista:

13. Comisión Israelita del PC, Bases para la tarea partidaria en la colectividad judeoargentina, 1970. Del Archivo personal de Raquel Malaj, Lanús, 2007.

14. Cincuenta años de la prensa judia progresista en la Argentina 1923-1973, Buenos Aires: Comité Editor, 1973.

15. Aunque disperso, su trabajo fue abundante. Contribuyó con diversas traducciones literarias del ídish al castellano; junto a Luis Goldman y Mina Fridman Ruetter tradujeron a Scholem Aleijem y otros clásicos idishistas. Algunos de sus libros publicados (todos en Buenos Aires y de edición partidaria) fueron Por tierras de pan y paz (1954); La paz salvará a Israel (1956); La invención del antisemitismo soviético 
el semanario Tribuna (1952-1961) y la revista quincenal Tiempo (19681989). ${ }^{16}$ Rubén era hijo de inmigrantes judíos polacos de origen humilde, radicados en la colonia de Moisés Ville, en la Provincia de Santa Fe. ${ }^{17}$ A los 17 años se trasladó a Buenos Aires donde trabajó, estudió, militó y conoció a Myriam, una joven judía y comunista, nacida en 1923 en el seno de una familia religiosa. En 1950 y 1952 nacieron sus hijas, Paula y Ana Luz. La familia vivió en un departamento alquilado en el barrio Once. Su condición de "comunista fichado" le impedía sacar un crédito para comprar una casa propia, pero también Sinay creía que si alquilaba, ante una redada policial, era más fácil escapar sin perderlo todo. Después de haber estado preso durante el peronismo en las cárceles de Devoto y Neuquén, afirmaba que lo más seguro era trabajar en su casa, y alli pasaba interminables horas tras la máquina de escribir. La familia subsistía con un pequeño sueldo que le otorgaba el partido y algún sobrante de las publicaciones que su esposa Myriam vendía por los barrios dónde había shules icufistas. La situación económica fue muy grave en ciertos años, pero Sinay sostenía que "la palabra y la acción debían ser parte de un todo coherente para un militante, y de esa forma había que vivir". Aquella coherencia implicaba rechazar el mundo consumista y el progreso económico individual mientras existiera gente que pasara hambre, y así vivió, fiel a sus ideales, que defendió con vehemencia. Desde su incorporación a Tribuna, Sinay tomó la posta del periodismo militante iniciado en ídish por el obrero gráfico Máximo Rozen en los años 20, el escritor Pinie Katz (1980) en los 30 y el actor Ioel Linkovsky (1980) en los 40. En el comedor de su pequeño departamento, Sinay recibía a sus camaradas del partido; Orestes Ghioldi y Victorio Codovilla un día, y al siguiente a los icufistas; sus amigos Sansón Drucaroff o Iosl Freidkes. Para entonces, el diagnóstico del PCA frente a la realidad y estructura socioeconómica argentina no había variado demasiado de los tiempos anteriores: se trataba de un capitalismo insuficiente, dependiente del imperialismo y los latifundios semifeudales, que requería de un proceso revolucionario por etapas. Para afrontar la primera, "democrático-burguesa, agraria y antiimperialista", la clase obrera necesitaba aliarse con la burguesía nacional "progresista". De esa manera, la senda reformista consolidada en 1935

(1963); La verdad sobre el conflicto en el Cercano Oriente (1967) y La URSS y el Cercano Oriente (1972), además de numerosos artículos y columnas en Tribuna y Tiempo.

16. La Revista Tiempo apareció en todas sus ediciones bajo la dirección y propiedad del dirigente y abogado Julio Schverdfinger, pero Sinay fue el verdadero director y editorialista.

17. La biografia de Rubén Sinay fue elaborada por la autora en base a una serie de entrevistas realizadas a sus hijas, varios activistas del ICUF y otras personalidades que lo conocieron, entre los años 2006 y 2010. 
se mantenía casi inalterable. Ya fuera bajo la forma de la alianza que dio origen a la Unión Democrática para enfrentar a Perón en 1946 o llamando a conformar un Frente Democrático Nacional en 1955, el partido seguía manifestando la necesidad de una alianza democrática y pacífica para llegar al socialismo y enfrentar a la "reacción" (Camarero, 2014: 31-50; Staltari, 2014: 11-30). De acuerdo con este esquema marxista sustentado en el materialismo histórico, Sinay afirmaba que las instituciones estaban destinadas a evolucionar, cumplir su ciclo y luego desaparecer en su transición a una sociedad igualitaria, incluso las icufistas. Sostenía que en la URSS la colectividad judia ya no necesitaba ni quería entidades particulares porque sus miembros tenian las mismas posibilidades y derechos que todos los demás ciudadanos; las bondades del modelo soviético no tenían límites en los escritos de Sinay. En 1969, cuando judíos de la URSS presionaban internacionalmente por migrar al Estado de Israel y denunciaban antisemitismo por parte del gobierno de Leonid Brézhnev, el partido organizó un viaje para los dirigentes del ICUF. En esa coyuntura -como cuando habian llegado las noticias sobre los crimenes de Stalin a los escritores judios en agosto de 1952- el objetivo era que los icufistas vieran con sus propios ojos la "falsedad" de aquellas acusaciones. Una vez en Moscú, había quienes percibian algunas fallas en el "perfecto sistema socialista"; los taxistas les habian cobrado en exceso y los moscovitas los atosigaban en la calle queriendo vender artesanías o pidiendo dólares. No obstante, en la reunión diaria de evaluación que el grupo de viajeros realizaba en el hotel, pocos se animaban a comentar los problemas que veían. Un activista que participaba, recordaba que Sinay encontraba explicaciones para justificarlo todo, hasta las cuestiones más triviales. Negaba cualquier tipo de critica, por insignificante que fuera y, sin embargo, al final de la travesía, estalló de furia al ver que la realidad no se adaptaba a su idealismo:

Después de la tercera vez que se habian acercado unos rusos a pedir cambiar rublos por dólares, cuando estábamos yendo al mausoleo de Lenin, íbamos cruzando y a unos cincuenta metros vemos un muchacho que se va acercando. Yo le anticipé a Sinay: "ese muchacho va a querer que le cambiemos dólares". Efectivamente, cuando empezó a decir "change, chan$g e "$, Sinay escuchó y je puso loco!, jle salían rayos láser de los ojos que atravesaban los lentes gruesos que usaba! empezó a gritar: ¡politzia! ipolitzia! ¡Terrible! ¡Le agarró un ataque! [...] Porque eso que pasaba no formaba parte de su idealismo [...] la gente como Sinay no podía aceptar que podían pasar esas 
pequeñas cosas, ¡menos aún iban a aceptar que pasaban cosas más graves! ${ }^{18}$

Su idealismo prosoviético también era lente para analizar el conflicto palestino-israelí. Sinay discutía principalmente con la izquierda de Hashomer Hatzair (herederos del Linke Poale Sion) quienes se expresaban a través del diario Nueva Sion. Los acusaba de "pararse en la vereda antisoviética" y en vez de bregar por la paz, colaborar con los "sectores reaccionarios" sionistas, quienes buscaban desprestigiar a la URSS y no comprender que la política exterior soviética no hacia más que equilibrar las fuerzas internacionales y quebrar el monopolio de armas estadounidenses en Oriente Medio. En las acaloradas discusiones políticas era enérgico y se ofuscaba con quien criticara a la URSS. En 1967, un grupo de activistas conocido como el "grupo de los trece", había abandonado el ICUF por desacuerdos con la línea sectaria y antisionista durante la Guerra de los Seis Días. Uno de ellos, Gregorio Lerner, dirigente de los shules y miembro activo de la Comisión Israelita del PC, recordaba las discusiones ideológicas sobre las líneas internacionales que emanaban del partido. En una oportunidad, y siendo dirigente comunista, Lerner se manifestó en contra de la invasión soviética a Hungría de 1956, a lo que Sinay respondió con una frase muy recurrente en la ortodoxia partidaria: "los compañeros que critican las acciones de la URSS no son verdaderos progresistas y colaboran con el enemigo fascista". ${ }^{19}$ Así como Lerner, otros recuerdan sus duros calificativos para quienes osaran dudar del paraíso socialista: "reaccionario agente del imperialismo" o "traidor bundista". Aquellas manifestaciones exponian la poca libertad para discrepar en las filas del partido, pero en el ambiente de las instituciones icufistas se generaba una tensión particular: la dificultosa alianza con la burguesía progresista judía, "clase útil" para la campaña financiera del PC, pero a veces muy dificil de "esclarecer" ideológicamente. Finalmente, la lógica bipolar de un mundo divido entre amigos y enemigos, yanquis o marxistas, explotadores y explotados, burgueses y proletarios, emergía una y otra vez en las visiones más radicalizadas como las de Sinay. En su vida privada era un hombre de pocas palabras, padre y marido amoroso que escribía poesías y creía con fervorosa pasión en sus ideales. Su obra dejó huellas en casi todos los temas del mundo icufista, entre ellos, la educación judeo-progresista.

18. Entrevista de la autora a Israel Zacutinsky, Lanús, marzo de 2008.

19. Entrevista relevada en el Archivo de la Memoria del Centro Marc Turkow (AMIA): Gregorio Lerner, entrevistado por Efraim Zadoff en Buenos Aires, 1986. 


\section{¿Cómo deben educar nuestras escuelas?}

Surgidos en los años del frentepopulismo, en los shules convergieron elementos pedagógicos de la cultura idishista, la escuela activa, la pedagogía colectivista y el normalismo argentino generando prácticas híbridas. Las obras de Domingo F. Sarmiento y Mariano Moreno convivieron con las de Antón Makarenko, Janusz Korczak, Federico Froebel y John Dewey, entre otros. Tal como en el entorno del PC (Carli, 2005), en los shules coexistian distintas visiones educacionales. En 1952, luego de la expulsión de AMIA, el Consejo Central del ICUF decidió inaugurar el Mitl-shul, una suerte de escuela secundaria para formar sus propios maestros judeo-progresistas. Los cursos, dictados por figuras destacadas del ambiente partidario incluyendo a Héctor Agosti, funcionaron hasta 1969 (Visacovsky, 2015: 236-241). A través de ellos, autores como José Ingenieros o Aníbal Ponce llegaban a las bibliotecas icufistas, pero también las experiencias y obras de Florencia Fossatti en Mendoza, el maestro uruguayo Jesualdo, Luis Iglesias en la provincia de Buenos Aires, Rosita Ziperovich y las hermanas Olga y Leticia Cossettini en Santa Fe, Berta Perelstein de Braslavsky en la Universidad de Buenos Aires y otros educadores comunistas y socialistas. En el plano político, seguía incólume el mandato del PCA de "acriollar" a sus seguidores y recuperar presencia en el mundo de los trabajadores. En ese sentido, también era necesario fomentar una educación progresista de carácter universal, y el ídish resultaba un impedimento, un "sectarismo" que obstaculizaba su llegada a todos los niños argentinos. Así, en pleno auge de la escolaridad idishista, con quince shules funcionando, y un tiempo antes de los efectos dramáticos del XX Congreso del PCUS en 1956, las posiciones que desplegaba Sinay con respecto a los shules postulaban que sus objetivos debian ser iguales a los de cualquier escuela progresista, "independientemente de si era o no judia, independientemente si enseñaba en ídish o en cualquier otro idioma". ${ }^{20}$ La escuela progresista debía "formar niños científicamente desprejuiciados y capacitados para interpretar dialécticamente la realidad social de la que formaban parte". ${ }^{21}$ Sin embargo, insistía, una educación científica y laica -o "liberal", como la había concebido Aníbal Ponce en Educación y lucha de clases (1937)no era suficiente para ser "progresista": el movimiento debía "formar gente que actuara e influyera con su accionar en el aceleramiento del progreso". ${ }^{22}$ Es decir, en la misma dirección ponceana, la educación debía

20. Rubén Sinay, "Objetivos de las Escuelas del ICUF”, Aporte, mayo-junio de 1956, año IV, n 11 , pp. 40-46.

21. Ídem, p. 42.

22. Ídem, p. 43. 
ejercer una influencia orientadora como la que Lenin había planteado para las masas obreras. Rubén Sinay era contundente: "la historia la hacen los hombres y la escuela progresista debe preparar hombres que hagan historia y que la hagan bien". ${ }^{23}$ Explicaba que "una vida mejor y más justa" dependía del contexto, del país y de la sociedad en la cual el niño vivía. En todos los países había escuelas progresistas, pero no todas funcionaban de la misma forma, sino que "cada una debía adaptarse a su realidad nacional" y el icufismo debía procurar que el niño se formara con "conciencia argentina". Ese énfasis era, en esa época además, un factor clave para diferenciarse de la creciente educación sionista, que contaba con apoyo político y económico internacional. Mientras el progresismo educaba "niños argentinos de origen judio", el sionismo formaba "niños judíos argentinos" con el objetivo de que en el futuro, éstos realizaran su aliá, es decir, migraran a poblar el Estado de Israel. En alusión a la educación de la izquierda sionista, Sinay afirmaba:

Reaccionaria es, en cambio, aquella escuela (por más formulaciones aparentemente progresistas que acuñe en la mentalidad infantil) que oriente al niño a aplicar los conocimientos adquiridos en una realidad social o geográfica distinta a la que conoce. El resultado de una enseñanza tal, es la desorientación del niño, el desarraigo de la realidad que vive y la nulidad e inoperancia de los postulados progresistas abstractos que pudiera habérsele suministrado. ${ }^{24}$

Los conceptos de "progresismo" y "cientificismo" debían situarse por encima de la especificidad judia. Se trataba de una propuesta "particular" (el judaísmo) que debía orientarse hacia "lo universal" (la sociedad toda). Finalmente, esas posiciones político-filosóficas marcaron el rumbo de las instituciones icufistas y su posterior apertura a la comunidad barrial; a nivel partidario, para "ganar a las masas obreras" y a nivel pedagógico para "educar a todos los niños en el progresismo". La paulatina desaparición de los shules en los 60 y 70 tuvo una estrecha relación con estas ideas, aunque no se debió sólo a ellas. Expresiones como las de Sinay, que relativizaban el idishismo en 1956, cuando escuelas y publicaciones en ese idioma estaban en pleno apogeo y siendo él mismo un talentoso conocedor y traductor del ídish, son indicios para comprender que el ocaso de los shules del ICUF debe ser enmarcado en un proceso gestado a lo largo de varios años. Mientras el PC de los inmigrantes necesitaba

23. Ibidem.

24. Ibidem. 
de las secciones idiomáticas para transmitir su ideología, la segunda generación necesitaría del castellano:

Si escuela progresista es lo que acabamos de definir y nosotros constituimos un movimiento progresista, ¿para qué, entonces, escuelas idiomáticas específicamente en ídish?, si igualmente o mucho mejor podriamos alcanzar esos objetivos a través de escuelas en castellano, tanto más cuanto este es el idioma corriente del niño. Este interrogante, que flota expreso o tácito en el ambiente de nuestros maestros jóvenes, interesa debatirlo aquí, no por simple deporte académico, sino porque se relaciona directamente o intimamente con la situación y futuro de nuestras escuelas. ${ }^{25}$

Efectivamente, la pregunta que encabeza la cita comenzó a ocupar las discusiones de las comisiones pedagógicas de los shules a finales de los años 50. Sin embargo, y aunque parezca paradójico, a pesar de avizorar un futuro sin escuelas idiomáticas, Sinay defendia la continuidad del shule por varios motivos; primero, porque habia padres judios que deseaban que sus hijos aprendieran el idish y asimilasen la cultura judeo-progresista y, segundo, porque la situación política del país impedia que el ICUF organizara escuelas progresistas en castellano. Para muchos militantes judios, el ídish todavía funcionaba como coraza protectora ante un escenario politicamente adverso. Salvo que aparecieran figuras policíacas empeñadas en hacer traducciones, como había planteado Matías Sánchez Sorondo, el ídish era para los veteranos comunistas una forma de protegerse. Además, había una tercera y fundamental razón para mantener los shules: "ganarle niños a la reacción judía y convertirlos en elementos útiles a la colectividad y al pueblo argentino". ${ }^{26}$ En definitiva, Sinay entendía que si en 1956 los judios hablantes de ídish necesitaban de esas escuelas para expandir su cultura progresista, "bienvenido" entonces el shule. Sin embargo advertía que, en cuanto "la fusión de nacionalidades", que aún estaba constituyendo al ser argentino, diese sus terceras y cuartas generaciones nativas, el ídish desapareceria; pero en cambio, la formación progresista perduraria en la sociedad. Entonces, la profecía de Sinay en plena actividad, mientras la editorial del ICUF traducía y publicaba en ídish numerosas obras y se proyectaba la expansión de los edificios, desconcertaba a varios de sus contemporáneos. Empero, él tenía clara aquella transformación: "los niños egresarán de las escuelas icufistas enriqueciendo la cultura argentina y seguramente vivirán el inevitable

25. Ídem, p. 44.

26. Îdem, p. 45. 
proceso objetivo de la historia, que traerá consigo la asimilación idiomática de la colectividad". ${ }^{27} \mathrm{El}$ proceso se inscribía en la dialéctica de la historia: primero habia que pasar por una etapa "aparentemente contradictoria", la de impulsar el ídish y las escuelas idishistas, para luego negarlas y, finalmente, ver en la sociedad argentina los logros de la educación judeo-progresista.

\section{Las voces de las lererkes}

En 1958, cuando el ICUF lanzaba su "Sexta Campaña Pro-cultura y Educación", solicitaba a los maestros trabajar con padres y alumnos para explicar el sentido político y la importancia de sostener escuelas judías con contenido progresista. Los problemas financieros eran recurrentes, pero con la creación de las cooperativas de crédito y los aportes de un público comprometido, los shules habían crecido en calidad de enseñanza y cantidad de alumnos. Según sus dirigentes, eso se debía a que funcionaban como un "oasis" frente al "oscurantismo" de la escuela pública estatal (a la que conceptualmente defendian, aunque evaluaban "tomada por las fuerzas de la reacción"). Sin embargo, después de la "lucha por la laica o libre", dónde el público juvenil icufista participó activamente, la situación de los shules comenzó a decaer y ya en 1962, en una mesa redonda organizada en Villa Lynch, activistas y docentes discutieron acerca de esta crisis. Una de las lererkes argumentaba que los niños concurrian con entusiasmo, aunque existia un porcentaje que lo hacía a desgano, obligados por sus padres. En este sentido, planteaba que "la primera dificultad con la cual se encontraban los niños era el ídish que, a pesar de hablarse en algunas casas, ya no constituía su lengua materna". ${ }^{28}$ Los chicos iban contentos por el trato afectuoso que se les brindaba, la forma en la cual se les enseñaba a razonar y el sentido crítico e independiente que se incentivaba en ellos, pero la cuestión idiomática aparecía como una dificultad. Entonces, la motivación que las familias tenían para enviarlos al shule parecía relacionarse más con los contenidos, el ambiente y el contraste con la escuela estatal, que con un interés genuino por el ídish. Esta situación encarnaba en un problema práctico y, ante la disyuntiva, algunas maestras optaban por priorizar la claridad del mensaje ideológico y daban sus clases en castellano. Para entonces, varias lererkes eran también nativas, puesto que se trataba de la joven generación egresada del Mitl-shul, que iría reemplazando a la camada inmigrante de la primera hora. Si bien el compromiso y afecto hacia toda aquella cultura persistía en la segunda

27. İdem, p. 46.

28. "La voz de nuestros maestros", Anuario, I.L.Peretz de Villa Lynch, 1962, p. 22. 
generación institucional, la mayoría asumía que la pérdida del idioma a largo plazo seria inevitable, aunque no acordaba con acelerar el proceso. El balance de las lererkes de 1962 concluía:

Las maestras se sienten cómodas y manifiestan que su visión progresista se debe al haber sido educadas en estas escuelas icufistas; agregan que aunque el idioma y la cultura judía no les resultan tan cercanos como a sus padres, no podrían de ningún modo rechazarlos. No se puede prever lo que sucederá dentro de varios años y cómo los procesos naturales y objetivos del tiempo van a influir sobre el posible debilitamiento de los elementos culturales judíos. Por ahora, sería un disparate facilitar subjetivamente y en forma apresurada este proceso. ${ }^{29}$

Otros testimonios similares y el hecho de que el jardin de infantes en castellano aumentara su matrícula mientras descendia la del shule, dejaba entrever que la integración idiomática constituía una realidad insoslayable. Más aún, el hecho de que la demanda partidaria por acelerar el pasaje al castellano ${ }^{30}$ haya tenido un peso relativo se comprueba al corroborar que aquella problemática no fue exclusiva del icufismo; sino que más lento o más veloz, todas las escuelas que enseñaban ídish, más allá de su ideología, atravesaron por el mismo proceso. Por supuesto, éste estaba extremadamente ligado al genocidio de la mayor comunidad hablante de ídish durante la Segunda Guerra Mundial y a la posterior adopción del hebreo como idioma oficial del Estado de Israel en 1948. La dirigencia israelí había colocado al idishismo europeo en el lugar del "pasado" de una nueva ciudadanía hebrea moderna y militarizada, pero basada en tradiciones ancestrales y preceptos religiosos. Entonces, mientras los judios progresistas reconocieron el valor de la creación del Estado israelí, pero rechazaron adoptarlo como "hogar nacional" y aprender su lengua, los sionistas, de izquierda a derecha, le dieron un lugar central en el desarrollo de la vida comunitaria. Las escuelas sionistas que se hicieron integrales (es decir, de doble jornada), introdujeron programas hebreos de estudio con contenidos ligados al proyecto sionista de "hacer aliá" (migrar o "retornar" a Israel). En menos de dos décadas, la transformación fue contundente; las horas destinadas al ídish quedaron en el olvido. Por otra parte, la juventud se rebelaba frente a la lengua de sus padres y abuelos; el ídish representaba "lo viejo" (Krupnik, 2006: 35). Asimismo, para los jóvenes icufistas el ídish

29. Ídem, p. 23.

30. Ver notas varias en la revista Aporte (1953-1956). Editada integralmente en castellano por la Federación de Instituciones Juveniles Israelitas de la Argentina (FIJIA), entidad vinculada a la Federación Juvenil Comunista. 
se vinculaba con "lo viejo", pero lo nuevo no era el hebreo porque el legado era "universal" y debía transmitirse en el "idioma nacional", es decir, el castellano. Inspirada en la revolución cubana, la juventud de izquierda se identificaba con su condición latinoamericana y participaba en universidades, partidos políticos y organizaciones civiles dónde lo judio dejaba de ser una marca diferencial. Por el contrario, para varios inmigrantes, sionistas o progresistas, la defensa a ultranza del ídish no sólo se relacionaba con la conservación de su propia historia, sino con la preservación de un mundo cultural exterminado por el nazismo. En definitiva, el proceso que implicaba aquella dolorosa pérdida, más allá de las tendencias generacionales e ideológicas, se vivia con contradicciones. Para ejemplificar una de ellas, cabe notar que mientras en 1955, derrocado Perón, los activistas del ICUF se dirigían al gobierno de la Revolución Libertadora y a la DAIA, clamando enfáticamente por recuperar la legalidad del uso del ídish que (ligado nuevamente al comunismo) había sido prohibido en 1953, hacia el interior del movimiento, la Comisión Israelita del PC insistía en apresurar el pasaje al castellano. ${ }^{31}$ En definitiva, una convergencia de factores sociales, políticos y económicos de la coyuntura argentina en particular y del escenario geopolítico internacional fue generando el cierre paulatino de los shules. Varias instituciones icufistas se fusionaron y sus actividades, tanto como su público, fueron mutando. La actividad educativo-recreativa adquirió centralidad y la "Comisión Central de kinder clubes" heredó del Shul Rat (Consejo de Escuelas) la misión de resguardar la transmisión ideológica. Importantes personalidades del campo educativo a nivel nacional reconocieron en las experiencias icufistas "semilleros" de notables proyectos pedagógicos (Puiggrós, 2003; Paín, 2001).

\section{El ocaso de la escuela idishista: ¿la profecia de Rubén Sinay?}

En conclusión, se ha visto que varias circunstancias llevaron al cierre definitivo de los shules y, si bien la voz partidaria tuvo su lugar, no hizo más que amalgamar con ellas. Además, cabe mencionar la importancia que tuvieron en esto las dificultades financieras de los años 60, que aumentaban a medida que el país sufría las consecuencias de la inestabilidad política y económica. El sostén de los shules también estuvo afectado por la restricción al funcionamiento de las cooperativas de crédito nacidas dentro de la red icufista, durante el gobierno de Onganía (Plotinsky, 2009). Entonces, más allá del discurso partidario, la historia muestra motivos concretos en el declinar de los shules: pro-

31. Ibídem. 
blemas financieros, desinterés de la juventud nativa por el aprendizaje del ídish, y un idioma que ya no tenía territorio donde ser hablado. En cuanto a la citada dispersión del público juvenil icufista, además del ámbito universitario, la Federación Juvenil Comunista ocupó un lugar destacado (Gilbert, 2009: 183-187): ¿qué sentido tenía entonces, seguir traduciendo del ídish y leyendo a Sholem Aleijem mientras Mao Tse Tung estaba cambiando la historia?; ¿para qué enseñar ídish a los niños, si ya no existía lugar dónde hablarlo?, y más aún ¿para qué enseñar en ídish, cuando lo importante eran los "contenidos progresistas" y no la lengua de transmisión? Las preguntas aparecieron una y otra vez en los debates sesentistas. Los partidarios de acelerar el proceso proclamaban el pasaje al castellano para "llegar a las masas trabajadoras" e integrar a los jóvenes, y quienes resistian, en cambio, trabajaban para que el ídish resultara ameno e interesante a los niños. El impacto final llegó a mediados de la década. En el marco de nuevas necesidades sociales, emergió con éxito la "escuela estatal de jornada completa" (Pastorino, 2000). Las primeras experiencias habian resultado muy exitosas y pronto creció esa modalidad, poniendo a las familias progresistas ante el dilema de tener que optar entre enviar a sus hijos a escuelas de jornada completa o mantener la rutina de dos escuelas; la estatal por la mañana y el shule por la tarde. En el IX Congreso del ICUF de 1968, cuando quedaban sólo tres shules funcionando, se discutió aquella problemática. La opción para darles continuidad era modernizarlos, adoptar el curriculum oficial y transformarlos en integrales (tal como lo estaban haciendo las escuelas sionistas). Sin embargo, aquella decisión generaba agudas polémicas. Quienes estaban a favor, los menos, argumentaban que era la única posibilidad de salvarlos, pero quienes estaban en contra, sostenían que una escuela idishista de doble jornada promovía la exclusión del niño judío de la escuela estatal y la sociedad argentina. Además, constituia una alternativa privada de altos costos, accesible sólo a quienes podian pagarla, lo cual iba en contra del espíritu de la Ley 1.420. Frente a este dilema, votaron padres, maestros y activistas en todas las entidades adheridas al ICUF. Las posiciones que prevalecieron fueron a favor de no competir con la escuela estatal y fortalecer la educación extraescolar en castellano de la red icufista. ${ }^{32}$

La decisión por la plena integración del niño "argentino de origen judío" a la escuela pública daba por terminado el tiempo del shule pero, a su vez, concluía la más fructífera etapa de desarrollo institucional. En 1969 egresaron los últimos alumnos del Mitl-shul y en 1976 ya no había inscriptos para sostener el shule (primaria). El jardín de infantes en castellano, sin embargo, siguió creciendo hasta la década del 80 por

32. Informe Final de la Comisión de Educación del IX Congreso del ICUF, 1968. 
su nivel pedagógico de excelencia y por no competir, sino complementar, la oferta estatal. La gran concurrencia a las actividades de kinder clubes y Zumerland impulsó a la dirigencia icufista a sostener que la educación judeo-progresista podía transmitirse a través de esos espacios, y en castellano. Finalmente llegaba la hora en la cual se cumplía la profecía de Rubén Sinay: si el objetivo era formar "argentinos" comprometidos con las causas de su tiempo, ¿para qué enseñar en ídish?

\section{Bibliografia}

Altamirano, Carlos (2001), Peronismo y cultura de izquierda, Buenos Aires: Temas.

Avni, Haim (1983), Argentina y la historia de la inmigración judia, 1810-1950, Jerusalén-Buenos Aires: Universitaria Magnes-Universidad Hebrea de Jerusalén.

Bilsky, Edgardo (1989), "Etnicidad y clase obrera: la presencia judía en el movimiento obrero argentino", Estudios Migratorios Latinoamericanos, año IV, $\mathrm{n}^{\circ} 11$, pp. 27-47.

Camarero, Hernán (2007), A la conquista de la clase obrera. Los comunistas y el mundo del trabajo en la Argentina, 1920-1935, Buenos Aires: Siglo XXI.

- (2014), "Tras las huellas de una ilusión: el Partido Comunista argentino y sus planteos del Frente Democrático Nacional (1955-1963)", Archivos, año III, $n^{\circ} 5$, pp. 31-50.

Campione, Daniel (2007), "El Partido Comunista de la Argentina. Apuntes sobre su trayectoria", en Elvira Concheiro, Massimo Modonesi y Horacio Crespo (2007), El comunismo: otras miradas desde América Latina, México: UNAM.

Carli, Sandra (2005), Niñez, pedagogía y politica, Buenos Aires: Miño y Dávila.

Devoto, Fernando (2004), Historia de la inmigración en la Argentina, Buenos Aires: Sudamericana.

- (2015), "Prólogo", en Nerina Visacovsky, Argentinos, judios y camaradas tras la utopía socialista, Buenos Aires: Biblos.

Diamant, Ana y Jorge Feld (comps.) (2000), Zumerland, Colonia. Proyecto y memorias, Buenos Aires: Zumerland.

Díaz, Javier, "El anarquismo en el movimiento obrero judío de Buenos Aires (1905-1909)", Archivos, año IV, no 8, pp. 119-140.

Feierstein, Ricardo (2007), Vida cotidiana de los judios argentinos. Del gueto al country, Buenos Aires: Sudamericana.

Gerchunoff, Alberto (2009), Los gauchos judios [1910], Buenos Aires: Agebe. Gilbert, Isidoro (2009), La Fede, Buenos Aires: Sudamericana.

Halperin Donghi, Tulio (2003), La Argentina y la tormenta del mundo, Buenos Aires: Siglo XXI.

Jmelnizky, Adrián y Ezequiel Erdei (2005), La población judía de Buenos Aires, Buenos Aires: Joint-Amia. 
Katz, Pinie (1980), Páginas selectas, Buenos Aires: ICUF [trad. del ídish, Mina Fridman Ruetter].

Kinoshita, Dina Lida (2000), "O icuf como uma rede de intelectuais", Universum, Talca, $\mathrm{n}^{\circ} 15$, pp. 377-398.

Krupnik, Adrián (2006), “¿Qué les pasa con el ídish a estos ídishes que escuchan a los Beatles y hablan de revolución?”, en Perla Sneh (comp.), Buenos Aires idish, Buenos Aires: Gobierno de la Ciudad de Buenos Aires.

Laubstein, Israel (1997), Bund. Historia del movimiento obrerojudio, Buenos Aires: Acervo Cultural.

Linkovsky, Ioel (1980), Escritos, Buenos Aires: Verbo [trad. del ídish, Rubén Sinay].

Paín, Abraham (2001), "Del adjetivo al sustantivo. Influencia de Zumerland y el kinder club sobre colonos y maestros", París: mimeo.

Pasolini, Ricardo (2013), Los marxistas liberales, Buenos Aires: Sudamericana.

Pastorino, Héctor Oscar (2000), La escuela de jornada completa, Buenos Aires: Caminos.

Plotinsky, Daniel (2009), "BCRA y cooperativismo de crédito. Una relación conflictiva (1958-1969)", ponencia en las XXI Jornadas de Historia Económica, Buenos Aires.

Puiggrós, Adriana (2003), ¿Qué pasó en la educación argentina?, Buenos Aires: Galerna.

Staltari, Silvana (2014), "El Partido Comunista frente al peronismo: estrategia y tácticas políticas, 1945-1955”, Archivos, año III, nº 5, pp. 11-30.

Visacovsky, Nerina (2015), Argentinos, judios y camaradas tras la utopia socialista, Buenos Aires: Biblos.

- (2012), "Matías Sánchez Sorondo y las escuelas obreras judias: dos mundos en conflicto", Anuario IEHS, Tandil, vol. 25.

Zadoff, Efraim (1994), Historia de la educación judia en Buenos Aires, 19351956, Jerusalén: Amilat.

$$
* * *
$$

Titulo: “Rise and decline of the ICUF's Yiddish school in Argentina (1941-1968)”.

Resumen: En base a una investigación más vasta sobre la identidad de la izquierda judia en Argentina, este trabajo analiza el proceso de auge y ocaso de las escuelas idiomáticas y complementarias en ídish adheridas al Idisher Cultur Farband (ICUF) entre 1941 y 1968. Desde los años 20 y 30, sus principales activistas estuvieron comprometidos con el Partido Comunista y bajo el clima aliancista del frentepopulismo los shules icufistas se multiplicaron. Sin embargo, cuando en la década del 60 la generación nativa apareció en escena, la continuidad del shule y la enseñanza del ídish comenzaron a perder sentido para sus protagonistas. Este artículo explora diversos factores que explican aquel proceso. Si bien la línea partidaria para la colectividad judeo-argentina ocupó 
un lugar en esa transformación, un análisis más complejo devela también la importancia de otras variables de cambio social y político en el país y el mundo. Palabras clave: ICUF Argentina - Judíos comunistas - escuelas ídishes - Rubén Sinay

Abstract: Based on a more extensive research about the Jewish left identity
in Argentina, this paper analyzes the process of rise and decline of the Idisher
Cultur Farband (ICUF) between 1941 and 1968. During the twenties and thirties,
its main activists were committed to the Communist Party and under the alli-
ance atmosphere of the Popular Front, the Yiddish schools multiplied. However,
when the native generation appeared on the scene in the 1960s, the continuity
of the "shules" and the teaching of the Yiddish began to lose meaning for their
protagonists. This article explores several factors that explain that process.
Although the party line for the Judeo-Argentine community occupied a place
in this transformation, a more complex analysis also reveals the importance
of other variables of social and political change in the country and the world. Key words: ICUF Argentina - Jewish communist - Yiddish schools - Rubén Sinay 